\title{
Group B streptococcal infection presenting as sudden death in infancy
}

\author{
M BARNHAM AND D C HENDERSON
}

Departments of Microbiology and Histopathology, Friarage Hospital, Northallerton, North Yorkshire

SUMmary Two infants aged 3 and 8 months were found dead in their cots. Postmortem cultures yielded group B streptococci from multiple internal sites, and cytomegalovirus was also isolated from the lungs of one. These cases show the value of microbiological culture in the investigation of sudden infant death.

Serious infection with group B streptococci may occur at any age but has been seen most commonly in neonates. ${ }^{12}$ An early onset disease with respiratory distress and septicaemia or meningitis may develop within the first week of life as a result of acquisition of the organism from the mother at birth; this occurs particularly in babies of low birth weight and when there is prolonged or complicated labour or premature rupture of the membranes. Obstetric factors are thought to act by increasing the dose of the organism or the time the baby is in contact with it or by exposing the baby to the organism at an unusually early stage of development. ${ }^{3}$ Another component of the problem may be that young babies lack the protective effect of a commensal flora on the body surfaces. Later onset disease in neonates often features meningitis and is thought to be due mainly to cross infection from staff or other babies in the nursery.

Beyond the neonatal period serious group $B$ streptococcal infection becomes much less common. $^{2}$ In a review of reports to the Public Health Laboratory Service systemic infection in neonates outnumbered that in older infants by 10 to one. ${ }^{3}$ The sources and predisposing factors of infection in this later age group are largely unknown. We report two rapidly fatal infections in infants, one with a concurrent cytomegalovirus infection.

\section{Case reports}

Case 1. A 3 month old breast fed boy, who was developing normally, visited Yorkshire with his parents in December 1985. On the day after their arrival he was restless and sniffling, as though he had a congested nose. He was put to bed at $1300 \mathrm{~h}$ that day and found dead at $1630 \mathrm{~h}$.
Necropsy was performed on the second day after death. There was oedema and vascular congestion of both lungs and some congestion of the liver. The thymus and spleen were enlarged with weights of 40 and $35 \mathrm{~g}$, respectively (normal reference weights 10 and $16 \mathrm{~g}$ ). There was no macroscopic evidence of meningitis. Histological examination of the lung revealed an interstitial pneumonitis, but no intracellular inclusions were found in this or other tissues examined.

Postmortem specimens yielded a pure growth of tetracycline resistant group B streptococci from lung, spleen, and cerebrospinal fluid (CSF). Typing of the organisms, at the Division of Hospital Infection, Colindale, showed that they were all type $\mathrm{Ia} / \mathrm{c}$ and susceptible to phages in the Colindale group B streptococcal typing set. Culture of specimens in the department of virology, Leeds Public Health Laboratory, yielded cytomegalovirus from lung but not from nose, throat, or CSF.

Case 2. A healthy 8 month old girl, still partly breast fed, lived with her parents and one sibling in North Yorkshire. One day in December 1985 she developed a slightly hoarse voice and was noticed to be more 'clinging' than usual. The next day she was put to bed in seemingly normal health at $2030 \mathrm{~h}$ but was found dead the next morning.

Necropsy performed on the day after death showed petechial haemorrhages in the thymus and pericardium and oedematous, congested lungs weighing $180 \mathrm{~g}$ (normal reference weight $109 \mathrm{~g}$ ). The spleen was congested and the thymus weighed $30 \mathrm{~g}$ (normal reference weight $8 \mathrm{~g}$ ). Histology showed a focal interstitial pneumonitis, but no intracellular inclusions could be found.

Postmortem specimens yielded tetracycline resistant group B streptococci from the nose, both main bronchi, lung, blood, and spleen but not from CSF. Typing in the Colindale laboratory showed that all isolates were type Ia and resistant to bacteriophages. CSF culture yielded no viruses.

\section{Discussion}

The heavy growth of group B streptococci from multiple systemic sites in these infants is good evidence of the cause of infection and death. 
Meningitis is often seen as a feature of group B streptococcal infection at this age, and in one of our patients the organism was isolated from the CSF. The finding of cytomegalovirus in the lungs of the first patient could be simply coincidental, but it raises the possibility that acute viral disease might underlie and potentiate group B streptococcal infection in some patients.

An impressive aspect of these infections was the rapid course to death, giving no time to establish a diagnosis or begin treatment. A similar rapidly fatal course was noted in $50 \%$ of infants who died in a recent survey of group B streptococcal disease in Britain, ${ }^{4}$ including one baby who, like ours, was found dead in his cot. A few years ago one of us reported a young adult with systemic group B streptococcal infection who, in similar style, was unexpectedly found dead in his bed. ${ }^{5}$

The presentation and initial necropsy findings suggested a diagnosis of the sudden infant death syndrome, which has been defined as "the sudden unexpected death of an infant in which a thorough postmortem examination fails to reveal an adequate cause of death"; without microbiological culture the diagnosis of acute streptococcal septicaemia would have been missed.
We thank Drs M Mowbray and J Partha for their help in the investigation of these patients and for permission to publish the details, and the Division of Hospital Infection, Central Public Health Laboratory, Colindale, for typing the streptococci.

\section{References}

${ }^{1}$ Eickhoff TC. Group B streptococci in human infection. In: Wannamaker LW, Matsen JM, eds. Streptococci and streptococcal diseases: recognition, understanding and management. New York: Academic Press, 1972: 533-43.

2 Thirmoorthi MC, Dajani AS. Systemic infections due to group-B streptococci: a 7 year experience at a childrens hospital. In: Holm SE, Christensen P, eds. Basic concepts of streptococci and streptococcal diseases. Chertsey, Surrey: Reedbooks, 1982: 291-2.

${ }^{3}$ Parker MT. Infections with group B streptococci. J Antimicrob Chemother 1979: 5 (Suppl A): 27-37.

${ }^{4}$ Mayon-White RT. The incidence of neonatal group-B streptococcal disease in Britain. In: Holm SE, Christensen P, eds. Basic concepts of streptococci and streptococcal diseases. Chertsey, Surrey: Reedbooks, 1982: 305-6.

5 Barnham M. Rapidly fatal group B and G streptococcal infections in adults. $J$ Infect 1980; 2: 279-81.

6 Wigglesworth JS. Perinatal pathology. (Major problems in pathology. Vol 15). Philadelphia: W B Saunders, 1984: 418-29.

Correspondence to Dr M Barnham, Department of Microbiology, Friarage Hospital, Northallerton, North Yorkshire DL6 1JG, England.

Received 27 October 1986 